\title{
Perception of and Adaptive Capacities to Climate Change Adaptation Strategies and Their Effects on Rice Production: A Case of Pabna District, Bangladesh
}

\author{
Farjana Eyasmin ${ }^{1, ~}$, Bikash Chandra Ghosh ${ }^{1}$, Md. Akram Hossain ${ }^{2}$ \\ ${ }^{1}$ Department of Economics, Pabna University of Science \& Technology, Pabna, Bangladesh \\ ${ }^{2}$ Department of Economics, University of Rajshahi, Rajshahi, Bangladesh
}

Email address:

Farjanatonny825@gmail.com (F. Eyasmin), bikasheco_pust@ymail.com (B. C. Ghosh), ak_eco@yahoo.com (Md. A. Hossain)

*Corresponding author

\section{To cite this article:}

Farjana Eyasmin, Bikash Chandra Ghosh, Md. Akram Hossain. Perception of and Adaptive Capacities to Climate Change Adaptation Strategies and Their Effects on Rice Production: A Case of Pabna District, Bangladesh. Journal of Health and Environmental Research. Vol. 3, No. 1, 2017, pp. 8-21. doi: 10.11648/j.jher.20170301.12

Received: October 30, 2016; Accepted: January 13, 2017; Published: February 27, 2017

\begin{abstract}
Bangladesh is one of the most sensitive hotspot for climate change and climate-related extreme events which significantly affect agricultural production. As a result farmers' try to minimize the adverse affects by various adaptation strategies. The aim of the study is thus, perception of and adaption capacities to climate change adaption strategies and their effects on rice production in a moderate level of drought severity and groundwater depletion but greater cropping diversity area (Pabna District). To find out the actual trend of climatic variables (e.g., temperature and rainfall) fourty two years of climate data on temperature and rainfall (1972-2013) from the Bangladesh Metrological Department (BMD) for Ishwardi weather station were collected and analyzed using non-parametric Mann-Kendall test. The adaptive capacities of rice farmers were estimated quantitatively and categorized into high, moderate and low adaptive capacities. Double logarithmic regression model of Cobb-Douglas production function was used to quantity the effects of adaptive capacities of farmers on rice production. The data was obtained by conducting direct collaboration with 200 rice growers of Pabna District in the periods of July, 2015. The results of Mann-Kendall test revealed that an increase in annual temperature of $+0.014^{\circ} \mathrm{C}$ and decrease in annual rainfall -1.152 from 1972 to 2013 has been recorded for the Ishwardi station of Pabna District, Bangladesh which is similar with the farmers' perceptions. Result of adaptive capacities revealed that on the average the farmers' interviewed are moderately adaptive to climate change. The results of Cobb-Douglas production function identified that the degree of adaptive capacities, labour, use of fertilizer, farm size, education and extension contact have significant effects on rice production. It also indicates that the more a farmer has the ability to adjust to climate change strategies the more the rice output he or she obtain. Therefore, rice farmers should be empowered through better extension services for obtaining more rice output. Strengthening agricultural research and support services including information accessibility, education and training for improved crop culture practices, and expanded and efficient surface-water irrigation infrastructure are critically important for increasing the adaptive capacities of the farmers.
\end{abstract}

Keywords: Adaptive Capacities, Adaption Strategies, Climate Change, Cobb-Douglas, Rice, Bangladesh

\section{Introduction}

Climate is commonly as the weather over a long period of time [3]. The standard averaging period is 30 years [9]. If the averaging period is very lower than the standard it would be threatened to the globe. Now-a-days the period is smaller resulting the climate change, has become most complex and challenging issue in the globe. Around the globe, seasons are shifting, temperatures are climbing and sea levels are rising. Individuals research [1], and institutions such as the InterGovernmental Panel on Climate Change [24], the United Nations Development Program (UNDP) [43], the World Bank (2010) and Food and Agriculture Organization [18] have demonstrated that climate change is a reality and a primary 
environmental threat to sustainable development in the $21^{\text {st }}$ century. From 1906 to 2005 the global average surface temperature increased by $0.74[0.56 \text { to } 0.92]^{\circ} \mathrm{C}$. The linear warming trend over the 50 years from 1956 to 2005 was 0.13 [0.10 to 0.16$]^{\circ} \mathrm{C}$ per decades is nearly twice that for the 100 years from 1906 to 2005 [24]. IPCC has estimated that by 2100 , average temperatures will increase by between $1.4^{\circ}$ and $5.8^{\circ} \mathrm{C}$. IPCC also reported sea levels would rise by an average 0.09 to $0.88 \mathrm{~m}$ between 1990 and 2100 .

The global climate has changed and these changes are shown by more frequent and intensity as well as irregular changes of disasters such as floods, droughts, storms and Tsunami within and over years. These changes have largely impacted on social, economic and environmental systems and shaped prospects for sustainable agricultural and rural development [17]. However, the impacts of climate change will not be uniform across the globe and considerable differences are expected among different regions [33]. Surprisingly, the poorest countries, who are the least contributors to global climate change, are amongst the most vulnerable to climate change. Poor communities are not only located in high-risk areas, but their lack of economic and social resources means they are ill-equipped to adjust to the longterm changes in climate $[40,42,15]$ where half of the world's seven billion people take rice as staple food where more than $90 \%$ of its produced and consumed in Asia. So, the effect of climate change has already shown off its vulnerable effect to the rice production. Since a temperature increase of $0.5^{\circ} \mathrm{C}$ is projected to reduce rice output by $5.91 \%$ [44].

Agriculture is an important sector of the Bangladesh economy. Despite a declining share in the gross domestic product (GDP), agriculture remains the pillar of the Bangladesh economy. It represents the critical source of income for the majority of the population and directly employing about half of the total labour force [22]. Furthermore, rural communities, that represent the vast majority of the population, will continue to depend on agriculture even with structural change in the economy (World Bank, 2013). Rice accounts for $90 \%$ of the total food production in Bangladesh and occupies nearly four-fifths of the gross cropped area. As a crop, it is sensitive to changing climate related extreme events, such as flood, drought, cyclones [35] and groundwater depletion.

Climate change in Bangladesh is especially a serious concern since agriculture is the most vulnerable sector to the climate change. German watch released the 2016 Global Climate Risk Index which indicates a level of exposure and vulnerability to extreme events that countries should understand as a warning to be prepared for more frequent and more severe events in the future and according to this index Bangladesh ranked sixth [49] and at the same time it indicates how serious the problem is for Bangladesh. Moreover, according to an estimation of Intergovernmental Panel on Climate Change [18], due to change in rainfall patterns associated with increasing temperatures, flooding, prolonged droughts and salinity by sea level rise could cause decline in rice production in Bangladesh by $8 \%$ in the year of
2050 against 1990 as the base year [35]. Hussain [24] has predicted that due to the effect of high temperature, crop production of two most important rice varieties (Aus and Aman) will be declined by $1.5-25.8 \%$ for $A u s$ variety, and 0.4-5.3\% for Aman variety (Aus and Aman rice varieties are cultivated during monsoon season in Bangladesh) respectively in the year of 2050. Since rice is very sensitive to climate, environmental and soil conditions, any unfavorable changes in climatic factors (temperature, precipitation, relative humidity and bright sunshine duration) are expected to affect rice yield adversely. Despite these serious climates -related difficulties, Bangladesh may be able to develop adaptive responses that could mitigate these effects.

Two ways to get rid of climate change vulnerability: mitigation and adaptation. Since mitigation is the time consuming process; so adaptation, the adjustment strategies is only the way get rid of climate change vulnerability. Adaptation is a policy option for limiting the negative effects of climate change [30]. This policy option can reduce vulnerability both to slow-onset climate change (e. g. sea level rise and salinization) and to extreme climatic events, such as droughts and floods [11]. And vulnerability could be reduced by altering exposure, reducing sensitivity, and improving the adaptive capacity of the system [50, 39]. IPCC [18] defines adaptive capacity as the ability or potential of a human or natural system to respond successfully to climate variability and change so as to moderate potential risks or cope with consequences of extreme events such as, floods, heavy hail/snow events, heavy wind and dust storms, droughts and dry spells, heat waves and warm spells, cold spells. Farmers have many different options available to cope with climate change; some of the options are able to increase soil fertility and moisture, therefore being suitable for improving adaptation capacity; most options can sustainably increase crop yields. The most common adaptation options include changing crop varieties, irrigation, planting trees, crop and livestock diversification, soil conservation, early and late planting, increasing plant spacing, use of clay soil, and adjusting the level and timing of applying fertilizer [10; 14, 30, 37, 38, 51] Traditional and newly introduced adaptation practices can help farmers to cope with both current climate variability and future climate change [8]. In Bangladesh, Ghosh et al.[12], Masud et al. [53], Sarker et al. [54] and Alauddin. M and Sarker A. R., [2] found that changing planting dates, early maturing rice varieties, drought tolerant rice varieties, use of chemical/organic fertilizers, farming near water bodies, mixed cropping, improved irrigation, set up shallow tube well in pond, building of embankments, integration of trees in rice farms, crop rotation, short duration species selection, little pond digging to conserve rain water etc. are the common adaptation strategies to climate change. But there are many barriers to adaptation include lack of information, lack of access to credit and land, and water shortages [46, 51, 14].

Taking into consideration the combined effects of climate change on rice-intensive countries such as Bangladesh, an 
investigation of perception of and adaptive capacities to climate change adaptation strategies and their effects on rice production is necessary to find out or understand how the degree of adaptive capacities of farmers among existing adaptation strategies effects rice production appears essential. Farmers' perceptions of the long-term changes in climate variables and extreme weather events are important because farmers first perceive the changes and then, based on their perceptions, they make decisions about adaptation strategies. This research advances the existing literature in two important ways. First, it uses farm-level survey data and quantitative analysis (to focus specially on rice farmers' adaptive capacities to climate change adaptation strategies and their effects on rice production in moderate drought severity and groundwater depletion areas in Bangladesh). Second, adaptive capacity varies from farmer to farmer that's why degree of adaptive capacity among climate change adaption strategies also varies and of course it affects rice output. So, it is very essential to estimate the adaptive capacity to climate change adaptation strategies. But no studies have been done on adaptive capacities to climate change adaptation strategies and their impact on rice production in Bangladesh using micro data till now. Thus, the present study is an effort to improve our understanding about the rice farmers' perceptions, adaptive capacities to climate change adaptation strategies and their effects on rice production. It is very important for policy makers and technocrats to improve the farmers' adaptive capacities to climate change adaptation strategies as well as increasing rice productivity.

Section 2 reviews the relevant empirical evidence, while section 3 presents and discusses the methodology. Section 4 presents and discusses the empirical results of the study. Section 5 discussed the conclusion and policy implications of the findings.

\section{Literature Review}

Three bodies of literature are relevant to this study: (1) Perception of the climate Change; (2) Adaptive capacities to climate change adaptation strategies and (3) their impact on rice production. Apart from research undertaken on Bangladeshi farmers, which is reviewed in section 2.2 the bulk of the existing research that has investigated farm-level adaptation to climate change has been mostly in in Africa countries (Cameroon, Egypt, Ethiopia, Ghana, Kenya, Niger, Senegal, South Africa, Zambia and Zimbabwe) and to a lesser extent in Sri Lanka, Australia, Malaysia, Chaina, Nepal, Philipaine, and India. The result from this body of research is examined first.

\subsection{Evidence Excluded Bangladesh}

The role of the human perception is one of the most important questions. If we understood how a human perceives information and operates it - we would more precisely make the future forecasts and increase our efficiency". That's why Deressa et al. [14] consider perceiving climate variability is the first step in the process of adapting agriculture to climate change. A better understanding of farmers' concerns and the manner in which they perceive climate change is crucial to design effective policies for supporting successful adaptation of the agricultural sector. Further, it is also important to have precise knowledge about the type and extent of adaptation methods being taken up by farmers and need for further advances in existing adaptation setups. Hence, understanding how farmers perceive changes in climate and what factors shape their adaptive behavior is useful for adaptation research [33, 48]. Bewket [7] found that increased temperature and decreased rainfall are widely held perceptions; all respondents stated that they had observed increase in temperature and decrease in annual and seasonal rainfall amounts.

In America Brechin, [12] found that between 1989 and 2003, 24 percent to 40 percent of the respondents worried about greenhouse effects as a great deal, where 52 to 72 percent have felt this way for a number of years and worried about afair amount. In another research, Leiserowitz [31] contended that since the year 2000, large majorities (92 percent) of Americans were aware of global warming. Moreover, 74 percent of them argued that climate change was real and already underway. Meanwhile, 76 percent of the total population already viewed climate change as a somewhat very serious problem. Namafe (2009) also highlights that even Barrack Obama, the incumbent president of USA by the time this research was conducted, never considered climate change as a major pressing environmental issue compared to terrorism and others.

Oxfam (2008) surveyed two of Vietnamese provinces, Ben Tre and Quang Tri in May 2008 to take a snapshot of Vietnam, how poor families were experiencing climate change. The perception of many villagers and local leaders in these provinces was that climate was changing. In Uganda Okonya J. S., Syndikus K. \& Kroschel J. (2013) revealed weather-related events such as prolonged dry seasons, floods, storms, mudslides, extreme rainfall, and delayed/early rains have become more frequent. Ninety nine percent of all households interviewed had observed a change in the climate in the last 10 years. The highest impact had on crop production.

Wang et al. [47] also find that climate change indirectly affects crop production as farmers react to changes in market signals. Second, the economic research accounts for the ways in which changes in trade flows and prices (which are direct consequences of climate change effects in other countries) will impact China's agricultural sector. To recover this react they have already attempted to take adaptive strategies. They have different adaptive capacities.

Gupta, J. et al. [23] found out the question: How can the inherent characteristics stimulate the capacity of society to adapt to climate change from local through to national level is assessed? This can help to assess if the adaptive capacity to respond to climate change; and to focus on whether and how institutions need to be redesigned. This paper also briefly 
demonstrates the application of this Adaptive Capacity Wheel to different institutions.

G. A. Glwadys et al. [19] estimated that climate has changed and farmer's perceptions are in the line with the climatic data record. The study tries to examine the determinant of adaptation to climate change. However, only approximately half of the farmers have adjusted their farming practices to account for the impacts of climate change. Lack of access to credit was cited by respondents as the main factor inhibiting adaptation. So the adaptive capacities are also very poor. The analysis highlighted that household size, farming experience, wealth, and access to credit, access to water, tenure rights, off-farm activities, and access to extension are the main factors that enhance adaptive capacity.

Mabe, F. N. et al. [57] stimate the adaptive capacities of farmers to climate change adaptation strategies and their effects on rice production in the northern region of Ghana. The adaptive capacities of rice farmers categorized into high, moderate and low adaptive capacities. On the average, the farmers interviewed moderately adaptive to climate change. $\mathrm{He}$ founded that farmers with high adaptive capacities obtained higher paddy rice more than moderate and low adaptive farmers. Rice farmers should be empowered through extension services in order to attain high adaptive capacities status so as to help them obtain more rice output. Another studies performed by Mabe F. N., Sienso G. \&Donkoh S. [32] revealed different effects of the factors on farmer's choice of adaptation strategies. Farming experience, farm income, access to phones, mixed farming, farmers' perception on reduction in rainfall amount and access to weather information significantly and positively affects the choice of at least five climate change adaptation strategies. But lack of agricultural extension service, adult education programs, and agro climatic information centers may weak the adaptive capacities.

Okonya J. S., Syndikus K. \& Kroschel J. [40] revealed weather-related events have become more frequent and intense in Uganda. This has left most of the rural poor farmers' food insecure and their livelihoods threatened while gender of the household head and size of land owned significantly affected adaptation. Coping strategies towards extreme events included storing food, income diversification and digging drainage channels. Other strategies were planting trees; high-yielding, early-maturing, drought-tolerant, disease and pest-resistant varieties; planting at onset of rains; increased pesticides application among others. But there are available a very few number of strategies and the farmers experienced low adaptive capacities of the strategies.

\subsection{Evidence from Bangladesh}

Most studies that have examined adaptation to climate change in drought porn areas of Bangladesh without focusing their adaptive capacities and their impact on rice production. Only one study used quantitative method, using non parametric mann-kendall test and sen's slope [21].

Rakib, M. and Anwar, S. M. H. [42] examined the determinants of farmers' perception on climate variability in different specifications of household characteristics. The sample was adult farmers with at least 20 years of farming experience in the area. The research revealed that more than $80 \%$ of farmers believe that temperature in the district had become warmer and over $90 \%$ were of the opinion that rainfall timing had changed, resulting in increased frequency of drought.

Kamruzzaman, M. [27] explained determines and describe the perception of climate change of farmers. Most of the farmers $(69.3 \%)$ perceived that climate change started between last 5 to 15 years. They felt that both rainy season and cold season delays to start but ends early. Similarly, they believe that hotness has increased $(88.7 \%)$ and coldness has reduced $(60.0 \%)$. Farmers found a reduction in overall rainfall $(83.3 \%)$ and variation in wind speed, duration of strong wind. They felt the incidence of drought has been increased (73.3\%) and flood has been decreased (66\%).

Moniruzzaman, M. [36] performed a study on assess the people's perceptions and understanding on climate change to evaluate the awareness level of them on the impacts of climate change in the study area. The study revealed that a significant portions of the society wasobserving the extreme events of weather like cyclones and storm surges, coastal erosion, and the changes of sea surface i.e. climate change. But they were not aware enough regarding the impacts of climate change and variability; and have hazy knowledge about the climate change.

Islam, M. N. [26] conducted to determine the extent of the farmer's perception andagricultural adaptation to climate change in the severe drought porn area of Rajshahi Division Ishwardi and Lalpurupazila. The findings of the study indicate that the, farmer's perception about climate change was reasonable as majority of farmers claimed that precipitation was decreased, summer season temperature was increased, and winter season temperature was decreased The findings of the study also indicated that majority of the farmers had medium agricultural adaptation capability compare to farmers had low and few farmers had high agricultural adaptation capability.

Ghosh B. C. et al. [21] evaluates rice farmers' perception and climatic variability and adaptive capacities of rice farmers to climate change adaption strategies were also identified. The results revealed that an increase in annual temperature of $+0.04^{\circ} \mathrm{C}$. The adaptive capacities of rice farmers were estimated quantitatively and categorized into high, moderate and low adaptive capacities. Result ofadaptive capacities revealed that on the average the farmers' interviewed are moderately adaptive to climate change. As high adaptive farmers obtain higher amount of rice therefore, the more a farmer has the ability to adjust to climate change, the more the amount of rice he or she obtain. Rice farmers should be empowered through better extension services in order to attain high adaptive capacity status so as to help them obtain more rice output.

FAO [18] conducted a holistic analysis of the improvement of the improvement of the adaptive capacity in the face of climate variability. Their results showed thatrice was the crop 
most affected by drought, with recorded production losses up to $70 \%$. FAO [18] identified some major adaptations strategies implemented by farmers, including the excavation of ponds and deep tube-well facilitated irrigation, expansion of mango plantations, the cultivation of short-duration and drought-tolerant crop varieties and homestead gardening.

A research performed by Ghosh, B. C., Mamun, A. H. M. M., Islam, S. M. R., [20] on the climatic effect on rice production. The research founded that need to improve adaptive capacities strongly. The study revealed the significant effects of climatic variables on rice yields and these effects vary among the three rice crops. Increase in Temperature and Relative humidity and decrease in Rainfall have both positive and negative effects on the yield. In that case almost $52 \%$ farmers perceive that crop production has decreased.

Although above studies provided useful direction, these studies suffer from two limitations. First, the studies aren't focus on the adaptive capacities to climate change adaptation strategies and their impact on rice production. Second, most of the past cross-sectional studies used county or district level data. But these studies do not allow for the detailed socio-economic and demographic characteristics of farmers that are likely to affect the farmer's perception, their choice of adaptation, and its capacities, thereby, farm productivity.

As the $1^{\text {st }}$ study of its kind on Bangladesh, the current research breaks new ground in analyzing and enhancing farmer's adaptive capacities to climate change adaptation strategies and their impact on rice production. Specifically, this paper has the following research questions:

a) What are the impacts of climate change on rice production?

b) How the changes affect the rice production across the study area?

c) How do rice farmers perceive the impact of climate change on rice production?

d) How effectively farmers have to adapt to the available adaptation strategies?

e) What is the degree of farmer's adaptive capacities to adaptation strategies in minimizing the effects of climate change?

f) Is higher adaptive capacity equivalent to higher rice output and lower adaptive capacity equivalent to lower rice output?

\section{Methodology}

\subsection{Study Area and Sample Selection}

Both primary and secondary data were collected to complete the present study. Secondary data for different climatic variables (e.g. temperature and rainfall) was collected from Bangladesh Metrological Department, Dhaka for the Ishwardi weather station which covers the period 1972-2014. A cross-sectional survey to collect data by using random technique from farming households in the Ishwardi Upazila (also randomly selected) in Pabna District was adopted for this study. The survey ends up with 200 valid observations (excluding missing information). The rationale behind selecting Pabna District for the present study is that (i) it is characterized by high temperature and very low rainfall which make it severely drought-prone and (ii) rice farming is the major livelihood-supporting activity. To answer the research questions, the survey sought information on:

a) Farmers' perception about climate change, climatic variability, adaptation strategies and adaptive capacities to climate change adaptation strategies.

b) Socio-economic characteristics (e.g. age, gender, education level of the household head, household size)

c) Farm characteristics (farm size, ownership status production, production cost)

\subsection{Mann-Kendall Test}

By Mann-Kendall test, we want to test the null hypothesis $H_{0}$ of no trend, i.e., the observations $x_{i}$ are randomly ordered in time, against the alternative hypothesis $H_{1}$, where there is an increasing or decreasing monotonic trend. The data values are evaluated as an ordered time series. Each data value is compared with all subsequent data values. If a data value from a later time period is higher than a data value from an earlier time period, the statistic $\mathrm{S}$ is incremented by 1. On the other hand, if the data value from a later time period is lower than a data value sampled earlier, $\mathrm{S}$ is decremented by 1 . The net result of all such increments and decrements yields the final value of S. The M-K test statistic $\mathrm{S}$ is calculated using the formula:

$$
S=\sum_{k=1}^{n-1} \sum_{j=k+1}^{n} \operatorname{sgn}\left(x_{j}-x_{k}\right)
$$

The application of trend test is done to a time series $x_{k}$ that is ranked from $\mathrm{k}=1,2 \ldots \mathrm{n}-1$ and $x_{j}$, which is ranked from $\mathrm{j}=\mathrm{k}+1,2 \ldots \mathrm{n}$. Each of the data point $x_{k}$ is taken as a reference point which is compared with the rest of the data point's $x_{j}$ so that,

$$
\operatorname{Sgn}\left(x_{j}-x_{k}\right)=\left\{\begin{array}{ccc}
1 & \text { if } & x_{j}-x_{k}>0 \\
0 & \text { if } & x_{j}-x_{k}=0 \\
-1 & \text { if } & x_{j}-x_{k}<0
\end{array}\right.
$$

It has been documented that when $n \geq 8$, the statistic $\mathrm{S}$ is approximately normally distributed with the mean. $\mathrm{E}(\mathrm{S})=0$. The variance statistic is given as,

$$
\operatorname{VAR}(S)=\frac{1}{18}\left[n(n-1)(2 n+5)-\sum_{p=1}^{q} t_{p}\left(t_{p}-1\right)\left(2 t_{p}+5\right)\right]
$$

Here $\mathrm{q}$ is the number of tied groups and $t_{p}$ is the number of data values in the $p^{\text {th }}$ group. The values of S and VAR(S) 
are used to compute the test statistic $\mathrm{Z}$ as follows

$$
Z=\left\{\begin{array}{ccc}
\frac{s-1}{\sqrt{\operatorname{VAR}(S)}} & \text { if } & S>0 \\
0 & \text { if } & S=0 \\
\frac{S+1}{\sqrt{\operatorname{VAR}(S)}} & \text { if } & S<0
\end{array}\right.
$$

$\mathrm{Z}$ here follows a standard normal distribution. A positive (negative) value of $Z$ signifies an upward (downward) trend. To test for either an upward or downward monotone trend (a two tail test) at $\alpha$ level of significance, $H_{0}$ is rejected if the absolute value of $Z$ is greater than $Z_{1-\alpha / 2}$.

\subsection{The Sen's Estimator of Slope}

Some trends may not be evaluated as statistically significant even while they might have practical interest [55]. Linear trend analysis, Sen's slope method is used in this study to estimate the magnitude of the trend. Here, the slope ( $\left.Q_{i}\right)$ of all data pairs is computed as [56].

$$
Q_{i}=\frac{x_{j}-x_{k}}{j-k} \text { for } \quad i=1,2,3, \ldots \ldots \ldots \ldots \ldots
$$

Where, $x_{j}$ and $x_{k}$ are considered as data values at time $\mathrm{j}$ and $\mathrm{k}(\mathrm{j}>\mathrm{k})$ correspondingly. The median of these $\mathrm{N}$ values of $Q_{i}$ is represented as Sen's estimator of slope which is given as

$$
\begin{aligned}
Q_{i} & =T_{N+1 / 2}, \text { if } \mathrm{N} \text { is odd } \\
Q_{i} & =\frac{1}{2}\left(T_{N / 2}+T_{N+2 / 2}\right), \text { if } \mathrm{N} \text { is even }
\end{aligned}
$$

Sen's estimator is computed as $Q_{m e d}=T_{(N+1) / 2}$ if $\mathrm{N}$ appears odd, and it is considered as $Q_{\text {med }}=\left[T_{N / 2}+T_{N+2 / 2}\right] / 2$ if $\mathrm{N}$ appears even. At the end, $Q_{m e d}$ is computed by a two sided test at $100(1-\alpha) \%$ confidence interval and then a true slope can be obtained by the non-parametric test. Positive value of $Q_{i}$ indicates an upward or increasing trend and a negative value of $Q_{i}$ gives a downward or decreasing trend in the time series.

\subsection{Measurement of Farmers' Adaptive Capacities to Adaptation Strategies}

According to Klein [74], adaptive capacity to climate change is the ability of a system or an individual to adjust to climate change or climate variability so as to minimize the potential damages or cope with the consequences. Adaptive capacity varies from farmer to farmer based certain factors that are peculiar to each farmer. Adaptive capacity varies from farmer to farmer based on certain factors that are peculiar to each farmer. It is assumed that farmers are rational and as such they adapt to climate change in order to reduce its consequences. Some farmers have higher ability to adjust to climate change than others. Asante et al. [65] and Nakuja et al. [52] measured adaptive capacities of farmers by considering five attributes such as knowledge, use, availability, accessibility and consultation. The adaptation strategies considered in this research are the use of chemical/organic fertilizer, improved irrigation, farming near water bodies, early maturing rice varieties, drought tolerant rice varieties, mixed cropping, changing planting dates, integration of trees in rice farms, building of embankments, crop rotation and setup shallow tube well in pond. Adaptive capacities of farmers depend on certain factors or attributes such as their knowledge on and number of times they use a particular adaptation strategy. Other factors are the availability and accessibility of the adaptation strategy. Also, the number of consultations that a farmer makes on a particular adaptation strategy affect whether the farmer will be lowly or moderately or highly adaptive to climate change. In measuring the adaptive capacities quantitatively, farmers were asked to indicate their degree of attainment of each attribute. The highest degree of attainment of each of the attributes or factors affecting adaptive capacities was scored 1 where the lowest degree was given a score of 0.25 . The score level for a farmer with higher degree of attainment of each attribute is 0.75 . Lastly, the score level for high degree of each farmer's knowledge on each adaptation strategy was sought. In terms of knowledge, the higher the degree, the better knowledge the farmer has on a particular adaption strategy. Table 3.1 summarizes how each attribute was measured.

Table 1. Score Levels of Farmer's Achievement of Attributes.

\begin{tabular}{llllll}
\hline Degree & Scores & Knowledge & Use & Availability & Accessibility \\
\hline Highest Degree & 1.00 & Very well & Several & Very regular & Easily Accessible \\
Higher Degree & 0.75 & Well & Twice & Regular & Accessible \\
High Degree & 0.50 & Fairly well & Once & Occasionally & Not easily Accessible \\
Low Degree & 0.25 & Not Well & Never & Never & Twice \\
\hline
\end{tabular}

Source: Modified from Nakuja et al. [52] and Mabe et al. [57]

The adaptive capacity (AdapCap) of an $\mathrm{i}^{\text {th }}$ farmer to $\mathrm{j}^{\text {th }}$ adaption strategy is calculated as shown in equation (1) below:

$$
\operatorname{AdapCap}_{i j}=\frac{K_{i j}+U_{i j}+V_{i j}+A_{i j}+C_{i j}}{N_{A}}
$$

Where AdapCap $_{i j}$ denotes the adaptive capacity of an $i^{\text {th }}$ farmer to a $\mathrm{j}^{\text {th }}$ adaption strategy; $K_{i j}$, the knowledge of the $\mathrm{i}^{\text {th }}$ farmer on $\mathrm{j}^{\text {th }}$ adaption strategy; $U_{i j}$, the level of usage of $\mathrm{j}^{\text {th }}$ adaption strategy by $\mathrm{i}^{\text {th }}$ farmer; $V_{i j}$, the availability of 
innovations on $\mathrm{j}^{\text {th }}$ adaption strategy to $\mathrm{i}^{\text {th }}$ farmer; $A_{i j}$, accessibility of innovations on $\mathrm{j}^{\text {th }}$ adaption strategy to $\mathrm{i}^{\text {th }}$ farmer; $C_{i j}$, level of consultation on $\mathrm{j}^{\text {th }}$ adaption strategies by $\mathrm{i}^{\text {th }}$ farmer; $N_{A}$, the sum of applicable attributes.

The average adaptive capacity of farmers to $\mathrm{j}^{\text {th }}$ adaption strategy, AveAdapCap ${ }_{\mathrm{ij}}$ is calculated using the equation (4) below

$$
A_{v e A d a p C a p}{ }_{i j}=\frac{\sum \operatorname{Adap} \operatorname{Cap}_{i j}}{N}
$$

Where, $\mathrm{N}$ is the number of Observations.

Table 2. Degree of Adaptive Capacities.

\begin{tabular}{lll}
\hline Degree of Adaptive Capacities & Ranges of Indices for AdapCap $_{\mathbf{i j}}$ & Ranges of Indices for AveAdapCap $_{\mathbf{j}}$ \\
\hline Low Adaptive Capacity & $0<$ AdapCap $_{i j}<0.33$ & $0<$ AveAdapCap $_{i j}<0.33$ \\
Moderate Adaptive Capacities & $0.33 \leq$ AdapCap $_{i j} \leq 0.66$ & $0.33 \leq$ AveAdapCap $_{i j} \leq 0.66$ \\
High Adaptive Capacity & $0.66 \leq$ AdapCap $_{i j} \leq 1.00$ & $0.66 \leq$ AveAdapCap $_{i j} \leq 1.00$ \\
\hline
\end{tabular}

Source: Modified from Nakuja et al. [52] and Mabe et al. [57]

Based on the adaptive capacities of the attributes, three indices were established. Table 2 shows the categories of adaptive capacities (low, moderate and high) to which each farmer falls within. It also shows the categories of average adaptive capacities (low, moderate and high) of each adaption technology. Farmer $i$ is lowly adaptive to adaptation strategy $j$ if the adaptive capacity calculated falls in the range of $0<$ AdapCap $_{i j}<0.33$. The range for moderate and high adaptive capacities are $0.33 \leq$ AdapCap $_{i j} \leq 0.66$ and $0.66 \leq$ AdapCap $_{i j} \leq 1.00$ respectively.

\subsection{Empirical Model for Quantifying the Effects of Adaptive Capacities on Rice Output}

For quantifying the effects of adaptive capacities on rice output, a Cobb-Douglas production function is employed for this study. A Cobb-Douglas production function shows a technical relationship between inputs and output, specified as:

$$
Q_{i}=\beta_{0} K_{i}^{\beta_{1}} L_{i}^{\beta_{2}} \mu_{i}
$$

Where $\mathrm{Q}_{\mathrm{i}}$ is the total output of rice for $i^{\text {th }}$ farmer, $\beta_{o}$ is the constant, $K_{i}$ is the capital input for $i$ th farmer, $L_{i}$ is the labor input for $i$ th farmer, $\mu_{i}$ is the error term for $i$ th farmer and $\beta_{1}$ and $\beta_{2}$ are the slope coefficients for capital and labor respectively. The unit of measurement for rice output, capital and labour are kilograms, Bangladeshi Taka (Tk.) and mandays respectively.

An augmented Cobb-Douglass production is then specified as shown in equation (6) by including dummy variables such as extension contact (Ext), access to education $(E d u)$, adaptive capacity indicators and continuous endogenous variable inputs such as quantity of fertilizer (Fert), farm size $(F m S)$ and age of the farmer (Age). The variable „Extension contact $^{\text {ec }}$ is dummied 1 for farmers who have access to extension contact and 0 otherwise. A farmer with at least primary education is dummied 1 and 0 otherwise. $L a_{i}$ and $H A_{i}$ represent low and high adaptive capacities respectively. A farmer with low adaptive capacity is dummied 1 and 0 otherwise. On the other hand, high adapters are given a score of 1 and 0 otherwise. Quantity of fertilizer, farm size and age are measured in kilograms $(\mathrm{Kg})$, decimals $(\mathrm{dc})$ and years respectively.

According to Onumah et al. [76], the Cobb-Douglas production function restricts the return to scale to one. Even though, this is a limitation, Cobb-Douglas production function had been used by Battese (1997) for its simplicity. Therefore, following Battese [75], we use an augmented Cobb-Douglas production function for this study, which is specified as:

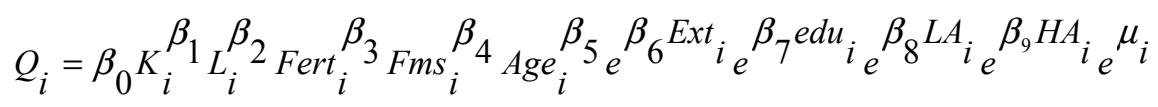

Taking natural log of equation (6) above gives the double log equation shown below:

$$
\ln \left(Q_{i}\right)=\beta_{o}+\beta_{l} \ln K_{i}+\beta_{2} \ln L_{l}+\beta_{3} \operatorname{lnFert}+\beta_{4} \ln F m_{l}+\beta_{5} \ln A g_{l}+\beta_{6} \operatorname{Ext}_{i}+\beta_{7} e d u_{l}+\beta_{8} L A_{i}+\beta_{9} H A_{l}+\mu_{i}
$$

\section{Result and Discussion}

\subsection{Trend of Climatic Variability}

For finding out the trend of climatic variability (e.g. temperature and rainfall) we use Mann-Kendall test. The Mann-Kendall test requires time series to be serially independent. The presence of serial correlation in the time series makes trend tests too liberal, i.e. the null hypothesis of no trend is rejected too frequently, specifically, if there is a positive serial correlation $[62,63]$. For this, von Storch and 
Navarra [64] suggest that the time series should be 'prewhitened' to eliminate the effect of serial correlation before applying the Mann-Kendall test. This study incorporates this suggestion and thus possible statistically significant trends in climatic observations $\left(x_{1}, x_{2}, \ldots \ldots \ldots \ldots . . ., x_{n}\right)$ are examined using the following procedures:

a) Compute the lag-1 serial correlation coefficient (designated by $r_{1}$ ).

b) If the calculated $\mathrm{r} 1$ is not significant at the 5\% level, then the Mann-Kendall test is applied to original values of the time series.

c) If the calculated $r_{1}$ is significant, prior to application of the Mann-Kendall test, thenthe'pre-whitened' time series may be obtained as $\left(x_{2}-r_{1} x_{1}, x_{3}-r_{1} x_{2}, \ldots \ldots \ldots . ., x_{n}-r_{1} x_{n-1}\right) \quad$ [66]

So, we remove the effect and analysis the trend. In the trend, annual temperature displays significant changes, with an upward trend identified for the Ishwardi Upazila. The average trend calculated for the study area has a Sen slope of +0.014 , implying that an increase in annual temperature of $+0.014^{\circ} \mathrm{C}$ form 1972 to 2013 has be recorded for the Ishwardi Upazila which is consistent with Chowdhury and Debsharma [59] and Mia [58] ointed out that temperature has been changed by using historical data of some selected meteorological station. Paratha sarathy et al. [60] and Divya and Mehritra [61] reported mean annual temperature of Bangladesh has increased during the period of 1895-1980 at $0.31^{\circ} \mathrm{C}$ over the past two decades. Karmakar and Shrestha [73] using the 1961-1990 data for Bangladesh projected that annual mean maximum temperature will increase to $0.4^{\circ} \mathrm{C}$ and $0.73^{\circ} \mathrm{C}$ by the year of 2050 and 2100 respectively.

Table 3. Trend of Annual Temperature and Rainfall for IshwardiUpazila, 1972-2013.

\begin{tabular}{lll}
\hline Statistics & Temperature & Rainfall \\
\hline Mann-Kendall Statistics & 279.00 & -216.00 \\
Kendall's Tau & 0.340 & -0.263 \\
Sen's Slope & 0.014 & -1.152 \\
P-value & 0.002 & 0.015 \\
Alpha & 0.05 & 0.05 \\
Test Interpretation & Reject $\mathrm{H}_{0}$ & Reject $\mathrm{H}_{0}$ \\
\hline
\end{tabular}

Note: $\mathrm{H}_{0}$ : There is no trend in the series, $\mathrm{H}_{\mathrm{A}}$ : There is a trend in series
From the above table we see that annual rainfall displays significant changes, with a downward trend identified for the Ishwardi Upazila. The average trend calculated for the study area has a Sen's slope of -1.152 , implying that decrease in annual rainfall of $1.152 \mathrm{~mm}$. 1972 to 2013 has be recorded for the Ishwardi Upazila which is consistent which is consistent with the study of Roy [78] and Zakaria [79], they also observes a significant downward trend for annual rainfall in the northern region of Bangladesh. So, climate of this region may change significantly. This decreasing trend of total rainfall may have the relationship to the decrease of water in rivers of this region, less evaporation as well as its consequences.

\subsection{Farmer's Perceptions of Climate Change}

As Ban and Hawkins [4] define 'perception' it is the process by which we receive information or stimuli from our environment and transform it into psychological awareness. It is interesting to see that people infer about a certain situation or phenomenon differently using the same or different sets of information. Knowledge, interest, culture and many other social processes that shape the behavior of an actor who uses the information and tries to influence that particular situation or phenomenon [68, 67]. Saarinen [69] talks about perception as an extremely complex concept and confines 'social perception' which is concerned with the effects of social and cultural factors on cognitive structuring of our physical and structural environment. This varies with the individual's past experiences and present sets or attitudes acting through values, needs, memories, moods, social circumstances, and expectations [69, 70] Farmers should perceive first that there is climate change in order to take necessary adaptive strategies [51]. The surveyed households were asked for any observed changes in temperature, rainfall, and drought, availability of ground water and availability of surface water over the past 20 years in order to ascertain their level of perception. Perceptions on climatic components were divided into three categories: increased, decreased, and don't know. Farmers' perceptions on each climatic parameter are presented below in Table 4.

Table 4. Farmers' Perception of Various Climatic Parameters over last 10 years.

\begin{tabular}{llllll}
\hline Farmers' Perceptions & Temperature (\%) & Rainfall (\%) & Drought (\%) & Availability of Ground Water (\%) & Availability of Surface Water (\%) \\
\hline Increased & 95 & 1.8 & 96 & 2 & 1.5 \\
Decrease & 2.7 & 96 & 1.13 & 96 & 96 \\
Don't Know & 2.3 & 2.2 & 2.87 & 2 & 2.5 \\
Total & 100 & 100 & 100 & 100 & 100 \\
\hline
\end{tabular}

Source: Computation from Field Survey, 2015

Table 4 indicate that $95 \%$ of the surveyed farmers have observed increasing temperature while only an insignificant $2.7 \%$ noticed a decreased in temperature, and for $2.3 \%$ of the respondent can't perceive. In case of rainfall $96 \%$ household heads observed a decline in yearly rainfall. $1.8 \%$ household heads perceived an increase in rainfall while don't know to $2.2 \%$ respectively. Almost $96 \%$ households noticed that frequency of drought has increased over the last 10 years while $1.79 \%$ households had no idea about the drought. In case of availability of ground water and availability of 
surface water $96 \%$ of the household heads perceived that availability of ground and surface water has decreased while $2.5 \%$ had no idea and $1.5 \%$ said that it has been increased.

\subsection{Degree of Adaptive Capacities of Farmers' to Adaptation Strategies}

The degree of adaptive capacities of rice farmers to the various adaption strategies is presented in Table 5. The respondents interviewed were highly adaptive to use of irrigation and use of chemical fertilizer. This is because their adaptive capacities are within the range of $0.66 \leq$ AdapCap $_{i j} \leq 1.00$. Among these adaption strategies with high adaptive capacities, use of irrigation and use of chemical fertilizer recorded the adaptive capacities of 0.81 and 0.71 respectively.

Table 5. Degree of Adaptive Capacities of Farmers.

\begin{tabular}{llll}
\hline Adaptation Strategy & Adaptive Capacities (AdapCap $_{\mathbf{i}}$ ) & Rank & Degree of Adaptive Capacities \\
\hline Use of Irrigation & 0.81 & 1 & High Adaptive Capacities \\
Use of Chemical Fertilizer & 0.71 & 2 & High Adaptive Capacities \\
Early Maturing Rice Varieties & 0.58 & 3 & Moderate Adaptive Capacities \\
Building of Embankment & 0.44 & 4 & Moderate Adaptive Capacities \\
Drought Tolerance Rice Varieties & 0.40 & 5 & Moderate Adaptive Capacities \\
Changing Planting Dates & 0.39 & 6 & Moderate Adaptive Capacities \\
Mulching & 0.31 & 7 & Low Adaptive Capacities \\
Integration of Trees in Rice Farms & 0.30 & 8 & Low Adaptive Capacities \\
Average & 0.49 & ----- & Moderate Adaptive Capacities \\
\hline
\end{tabular}

Source: Computation from Field Survey, 2015

The adaption strategies with moderate adaptive capacities are the early maturity rice varieties, embankment building, drought tolerance rice varieties, and changing planting dates. Out of the eight adaption strategies used, farmers are moderately adaptive to four of them. Among adaption strategies which farmers are moderately adaptive, the early maturity rice varieties had the highest adaptive capacity value of 0.58 whiles changing planting dates recorded the lowest of 0.39 . The adaptive capacities calculated for embankment building and drought tolerance rice varieties are equal with the value of 0.44 and 0.40 respectively. The respondents in the area have low adaptive capacity to the mulching and the integration of trees in rice farms. Mulching has the adaptive capacity value of 0.31 . The adaptive capacity value quantified for integration of trees in rice farms is equal with a value of 0.30 . Generally, the average adaptive capacity of the respondents is 0.49 . This implies that farmers in the study area are moderate adapters to climate change.

Table 6. Percentage of Degree of Adaptive Capacities of Responsibilities.

\begin{tabular}{llll}
\hline Adaptive Capacities & Mean Adaptive Capacity & Frequency & Percentage \\
\hline High Adapters & 0.73 & 30 & 15 \\
Moderate Adapters & 0.57 & 92 & 46 \\
Low Adapters & 0.30 & 78 & 39 \\
Average & 0.53 & 200 & 100 \\
\hline
\end{tabular}

Source: Computation from Field Data (2015)

Table 6 represents the percentage of the degree of adaptive capacities of respondents. Table 6 indicates that $39 \%$ out of 200 farmers interviewed are low adapter to the climate change adaption strategies. Also, $46 \%$ of the respondents are moderate adapters. On the other hand, only $15 \%$ of the respondents interviewed are high adapters. Though, majority $(46 \%)$ of rice farmers is moderate adapters to climate change; on the average, the farmers interviewed are moderate adapters. This is because, the mean adaptive capacity calculated is 0.53 which falls within the range of moderate adapters $\left(0.33 \leq\right.$ AdapCap $\left._{i j} \leq 0.66\right)$. This implies, averagely the farmers in the area do not have all necessary resources to aid them adapt highly and effectively to climate change.

\subsection{Interpretation of Regression Results}

Table 7 represents the Ordinary Least Square Method (OLS) regression results on the effects of adaptive capacities on rice production. These results were obtained by the estimating the double logarithmic augmented Cobb-Douglas production function specified in the equation (5). The Table 7 shown in below.

Table 7. OLS Regression Results: Adaptive Capacities as Determinants of Rice Production.

\begin{tabular}{lllll}
\hline Variables & Coefficient & Std. Error & t-statistics & Prob. \\
\hline $\ln (\mathrm{K})$ & 1.0897 & 0.783 & 1.3916 & 0.1657 \\
$\ln (\mathrm{L})$ & 0.260 & 0.144 & 1.793 & $0.075^{*}$ \\
$\ln ($ Fert $)$ & 0.298 & 0.076 & 3.921 & $0.000^{* * *}$ \\
$\ln (\mathrm{FmS})$ & 0.678 & 0.101 & 6.049 & $0.000^{* * *}$ \\
$\ln ($ Age $)$ & 0.5720 & 0.615 & 0.929 & 0.353 \\
Edu. & 0.5172 & 0.2698 & 1.916 & $0.0568^{* *}$ \\
Ext. & 0.087 & 0.487 & 1.798 & $0.073^{*}$ \\
LA & -0.1856 & 0.069 & -2.689 & $0.012^{* * *}$ \\
HA & 0.2336 & 1.002 & 5.682 & $0.000^{* * *}$ \\
c & 11.2939 & 3.0305 & 3.726 & $0.000^{* * *}$ \\
R- Squared & & & 0.897 & \\
Adjusted R-Square & & 0.752 & \\
F-Statistics & & & 51.0065 & \\
Prob(F-Statistics) & & $0.000^{* * *}$ & \\
\hline
\end{tabular}

Note: $* * *, * * *$ indicates $1 \%, 5 \%$ and $10 \%$ level of significance respectively. 
Before interpreting the results we have to first test the basic assumptions of the Ordinary Least Square (OLS) model i.e. Normality, Multicollinearity, Autocorrelation and Heteroscedasticity. After testing, we found that the resultsare free from multicolinearity, autocorrelation and heteroscadasticity problem and it also normally distributed which are shown in the appendix.

The results of the model are interpreted and discussed in the following paragraph. The results are obtained by estimating the double logarithmic augmented Cobb-Douglas production function specifies in equation (6). The coefficient of determination $\left(\mathrm{R}^{2}\right)$ value is $89.7 \%$. This value implies that the variations in labor, capital, fertilizer, farm size, age, education, extension contact and adaptive capacities explained about $89 \%$ of the variations in rice production. The F-statistics indicates that the overall regression is significant at $1 \%$ meaning that the independent variables jointly affected rice production. Note that rice is used in this study paddy rice.

From table 7, the amount of labor employed in man days (L), the capital in Tk. (k), fertilizer in kg (fert.), farm size in decimals (FmS.), are consistent with the a priori expectation. The amount of labor employed is significant at $10 \%$ level of significance. This implies that labor significantly affected the rice production. Since double logarithmic Cobb-Douglas Production function is used, the coefficients are the elasticity. So at $1 \%$ increase in the amount of labor employed will result in an increase in the quantity of rice production by $0.26 \%$. For Ghana Mabe et al. (2012) found that labor have positive and significant impact on rice production. Fertilizer application is significant at $1 \%$ level of significance. Therefore, quantity of fertilizer significantly affects the rice production in the study area. As such, $1 \%$ increases in the quantity of fertilizer increase the rice production $0.29 \%$. The number of decimals of land cultivated for rice is significant at $1 \%$ implies that farm size affect rice production. Hence, an increase in farm size by $1 \%$ increases the quantity of rice output by $0.67 \%$. Rice production is more responsive to area expansion than other input variables because farm size has the highest elastic value. These positive impacts of farm size on rice production are consistence with evidence for African studies [51, 77]. As adaption entails costs, large farms are more likely to adapt earlier than small farmers. Age and Capital (K) are not statistically significant that means they do not bear any meaning.

Education (Edu), extension contact (Ext), high adaptive capacity (HA) and low adaptive capacity (LA) are statistically significant thus affects rice production significantly. Education is significant at 5\% level indicate that an increase of 1 year education increase the rice production by $0.51 \%$. Evidence from Africa where farmers with higher educational level were likely to adapt better to climate change thus increase rice production [14] supports this finding. Extension contact (Ext) is statistically significant at $10 \%$ level which indicates an increase of $1 \%$ extension contact increase rice output by $0.08 \%$. Extension contact acts as a platform for information about new agricultural and adaptive technologies [70, 71]. Derressa et al. [14] also reported the positive impact of extension contact on the adoption of various adaptation strategies in the face of climate change. Farmers which have high adaptive capacity obtain $0.28 \%$ higher rice output than other and similarly farmers which have lower adaptive capacity obtain $0.17 \%$ lower rice output than others. This suggests that high adaptive farmers learn and use modern techniques in their farming activities which minimize the detrimental effects of climate change on rice production so; high adaptive capacity positively affects rice production where as low adaptive capacity negatively affects rice production this is similar with the studies of Mabe et al. [57] for Ghana.

\section{Conclusion and Policy Implications}

\subsection{Summary of Conclusion}

This study examined farmers' perception about climate change, adaptive capacities to climate change adaptation strategies and their impact on rice production. Farmers' perception appeared consistent with the relevant Ishwardi weather station compared to Bangladesh. The bulk of farmers in the study area adapted to climate change with a range of strategies. The adaptive response typified more a process of autonomous based on their adaptive capacities. The study determines that farmers adapt moderate adaptive capacities to climate change adaptation strategies. But other factors as education level of the household head, farm size, labor, fertilizer, low and high adaptive capacities affect the rice production.

\subsection{Policy Implications}

The findings of this study have several policy implications for enhancing the adaptive capacities to climate change adaptation strategies. These include scientific breakthroughs, the provision of stronger support services for farmers, training and awareness to the farmers to combat risk.

The need for the development and accessing the high yielding rice varieties, drought tolerance varieties in the study area has prompted scientific breakthroughs in rice production. Crop with short growing season will also be important as season variability is more common. The government should available the information about agriculture to the farmer as soon as possible by enhancing extension contact.

Therefore, rice farmers should be empowered through better extension services in order to attain high adaptive capacity status so as to compensate them in obtaining more rice output. Strengthening agricultural research and support services including information accessibility, education and training for improved crop culture practices, and expanded and efficient surface-water irrigation infrastructure are critically important for increasing the adaptive capacities of the farmers.

\section{Appendix}

Normality Test: Normality is used to inference for the 
hypothesis testing and thus estimates for the true coefficients. The error term is assumed to follow the normal distribution with zero mean and constant variance, so it can be a best linear unbiased estimator. The hypothesis for normality test is as follow:

$\mathrm{H}_{0}$ : The residuals are normally distributed.

$\mathrm{H}_{1}$ : The residuals are not normally distributed

Series: Residuals

Sample 1200

Observations 200

Mean

$-1.23 \mathrm{e}-15$

Median

0.041963

Maximum

0.666685

Minimum

$-0.636578$

Std. dev.

0.247370

Skewness

$-0.053146$

Kurtosis

3.472148

Jarque-Bera

0.419648

Probability

0.810727

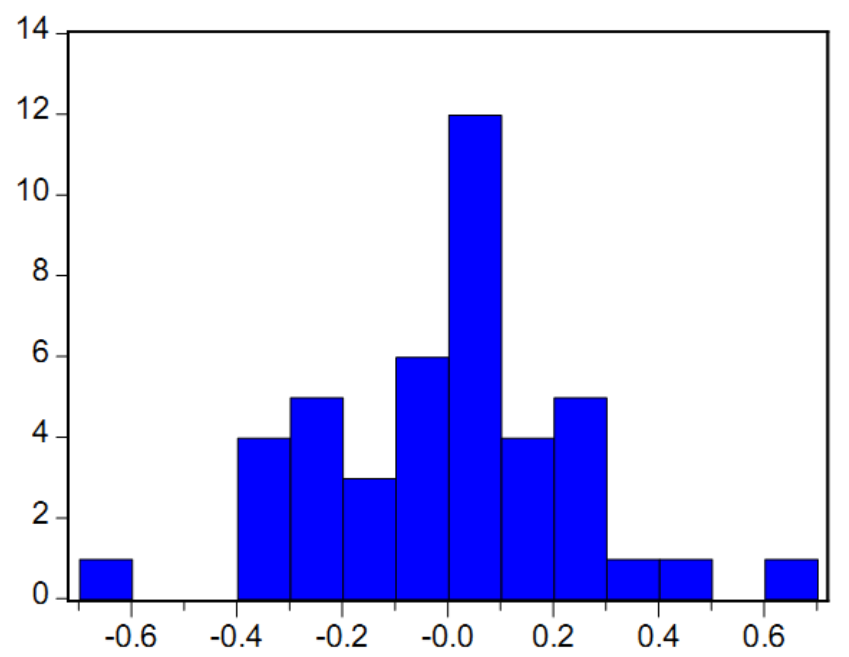

Figure A1. The Result from the Histogram Normality Test.

From the histogram, it seems that the residuals are normally distributed. Since the probability is 0.810727 and it is larger than the critical value which is $5 \%$ significant level.

Multicollinearity Test: Multicollinearity is the existence of strong correlation among the explanatory variables. If correlation coefficient thus computed is equal to or greater than 0.80 there exists Multicollinearity (Looms and Walsh, 1997).

Table A1. Correlation Matrix of Coefficient.

\begin{tabular}{lllllll}
\hline & Age & $\begin{array}{l}\text { Farm } \\
\text { size }\end{array}$ & Fertilizer & Labor & Capital & Education \\
\hline Age & 1 & & & & & \\
Farm size & 0.46 & 1 & & & & \\
Fertilizer & 0.32 & 0.74 & 1 & & & \\
Labor & 0.43 & 0.63 & 0.57 & 1 & & \\
Capital & 0.50 & 0.60 & 0.45 & 0.42 & 1 & 1 \\
Education & 0.71 & 0.30 & 0.49 & 0.31 & 0.65 & 1 \\
\hline
\end{tabular}

The test result show that the values of the correlation coefficient of all explanatory variables are the benchmark value i.e. 0.80 on the basis of the above results we reject the hypothesis of multicollinearity among the explanatory variables.

Autocorrelation Test: Since our model does not include any lag variable thus the existence of Autocorrelation can be tested with Geary Test. This is a non-parametric test, and suggests that expected number of runs be in between $\{\mathrm{E}(\mathrm{k}) \pm$ $\left.1.96 \sigma_{\mathrm{k}}\right\}$ with $95 \%$ confidence interval. The values of mean $[\mathrm{E}(\mathrm{k})]$ and variance $\left(\sigma_{\mathrm{k}}\right)$ are calculated as follows (Gujarati, 1995):

$$
\mathrm{E}(\mathrm{k})=\frac{2 n_{1} n_{2}}{n}+1 \text { and } \sigma_{k}^{2}=\frac{2 n_{1} n_{2}\left(2 n_{1} n_{2}-n\right)}{(n)^{2}(n-1)}
$$

Where,

$\mathrm{n}=$ Sample size

$\mathrm{n}_{1}=$ Number of positive residuals

$\mathrm{n}_{2}=$ Number of Negative residuals

$\mathrm{k}=$ Number of runs

The decision rule is that we don't accept the null hypothesis of randomness with $95 \%$ confidence if

$\left[\mathrm{E}(\mathrm{k})-1.96 \sigma_{\mathrm{k}} \leq \mathrm{k} \leq \mathrm{E}(\mathrm{k})+1.96 \sigma_{\mathrm{k}}\right]$

If the number of estimated runs $(\mathrm{k})$ falls in between the two values, then we accept the randomness of residuals, and thus reject the existence of autocorrelation.

In this case, there are,

$$
\begin{aligned}
& \mathrm{k}=90 \\
& \mathrm{n}_{1}=112 \\
& \mathrm{n}_{2}=88 \\
& \text { So, } \\
& \mathrm{E}(\mathrm{k})=99.56 \\
& \sigma^{2}{ }_{k}=43.86 \\
& \sigma^{2}=43.86 \\
& \left\{\mathrm{E}(\mathrm{k}) \pm 1.96 \sigma_{\mathrm{k}}\right\}=99.56 \pm(1.96 \times 6.62) \\
& =99.56 \pm(12.9752) \\
& =[112.53,86.58]
\end{aligned}
$$

The total number of runs in these calculations is 90 , which lie in between the two values so we accept the hypothesis of randomness of residuals and thus reject the existence of autocorrelation.

Heteroscadasticity Test: Homoscedasticity is another important assumption of the OLS, which means constant variance of the error term. In the present study, White test have been applied for detecting the problem of heteroscedasticity in the data.

The hypothesis made for the heteroscedasticity problem is:

$\mathrm{H}_{0}$ : There is no heteroscedasticity problem.

$\mathrm{H}_{1}$ : There is heteroscedasticity problem.

Table A2. The Result of White Heteroscedasticity Test.

\begin{tabular}{llll}
\hline F-statistic & $\mathbf{1 1 . 1 8 0 8 0}$ & Probability & $\mathbf{0 . 0 0 0 2 7 0}$ \\
\hline Obs*R-squared & 13.76465 & Probability Chi-Square & 0.071026 \\
\hline
\end{tabular}

The output results showed that Probability $0.071026>5 \%$, So we should accept the null hypothesis, indicating the absence of heteroscedasticity in the model. 


\section{References}

[1] Ackerman, F. and Stanton E. A., (2013) "Climate Impacts on Agriculture: A Challenge to Complacency?" Global Development and Environment Institution: working paper no. 13-01.

[2] Alauddin, M., Sharma, B. R., 2013. Inter-district rice water productivity differences in Bangladesh: an empirical exploration and implications. Ecol. Econ. 93, 210-218.

[3] AMS (2009): American Metrological Society: https://www.ametsoc.org/ams/index.cfm/about-ams/amsstatements/statements-of-the-ams-in-force/climate-change.

[4] Ban, A. W. Van den and H. S. Hawkins, (2000). Agricultural Extension, Second edition, Blackwell Science, UK. Bartlett, J. E., J. W. Kotrlik and V. C. Higgins., (2001). Organizational Research: Determining Sample Size in Survey Research. Information Technology, Learning, and Performance Journal, Vol. 19, No. 1, Spring 2001, pp. 43-50.

[5] Berhanu W; Beyene F. (2015); "Climate Variability and Household Adaptation Strategies in Southern Ethiopia" www.mdpi.com/journal/sustainability; ISSN 2071-1050

[6] Basak J. K., Ali M. A., Islam M. N. and Rashid M. A., (2010) "Assessment of the Effect of Climate Change on Boro Rice Production in Bangladesh Using DSSAT Model”, J. Civil Eng 38: 95-108.

[7] Bewket. W., (2012): Climate change perceptions and adaptive responses of smallholder farmers in central highlands of Ethiopia. International Journal of Environmental Studies 69: 507-523.

[8] Bilow t, Artner A, Siebert R, Sieber S (2010). Micro-level Practices to Adapt to Climate Change for African Small-scale Farmers. FPRI Discussion Paper 00953, Washington, D. C.: International Food Policy Research Institute.

[9] BOM (2007): Bureau of Metrology: http://www.bom.gov.au/climate/current/statements/

[10] Bradshaw, B., Dolan, H., \& Smit, B. (2004). Farm-level adaptation to climate variability and change: crop diversification in the Canadian prairies. Climate Change, 67 (1), 119-141.

[11] Branca, G., Sorrentino, A., Lipper, L. 2012a. Benefit-costs analysis of climate-related agricultural investments in Malawi: a case study. Paper. Paper presented at the 1st AIEAA Conference 'Towards a Sustainable Bio-economy: Economic Issues and Policy Challenges', 4-5 June, Trento, Italy

[12] Brechin, S. R. (2003): Comparative public opinion and knowledge on global climatic change and the kyoto protocol: the US versus the rest of the World? International Journal of Sociology and Social policy 23 (10), 106-134

[13] BMO, 2009. British Meteorological Office $<$ http:metoffice.gov.uk> 2010, December 15.

[14] Deressa, T. T., Hassan, R. M., Ringler, C., (2009): Assessing Household Vulnerability to Climate Change: The Case of Farmers in the Nile Basin of Ethiopia, Washington, DC: International Food Policy Research Institute Discussion Paper 00935.

[15] Enete, A. A., Amusa, T. A., (2010) "Challenges of Agricultural Adaptation to Climate Change in Nigeria: a Synthesis from the Literature" The Journal of Field Action, Vol: 4.

[16] FAO (2011). Climate Change and Food System Resilience in Sub-Saharan Africa. Food and Agriculture Organisation of the United Nations, Rome. 436 pp.

[17] Fischer G., Shah M. and Velthuizen, H. V. (2002) "Climate Change Agricultural Vulnerability" Institutional Institute for Applied System Analysis.

[18] Food and Agriculture Organisation (FAO) (2006), Livelihood adaptation to climate variability and change in drought-prone areas of Bangladesh. Food and Agriculture Organisation, Rome, Italy.

[19] G. A. Glwadys et al. (2009): Understanding Farmers' Perceptions and Adaptations to Climate Change and Variability: International Food Policy Research Institutions.

[20] Ghosh, B. C., Islam., S. M. R., Mamun. A. H. M. M. (2015); "Empirical evidence of climate change: Effects on Rice Production in Bangladesh" International Journal of Geology, Agriculture and Environment Science, vol.-3, Iss: 4, PP. 01-06

[21] Ghosh, B. C., Osmani. A. G. and Hossain. E. (2015). "Perception of and Adaption Capacities to Climate Change Adaption Strategies by the Rice Farmers: A Case of Rajshahi District in Bangladesh". Journal of Economics and Sustainable Development 6: 136-145.

[22] GOB 2011; Yearbook of Agricultural Statistics of Bangladesh, Ministry of Planning, Dhaka.

[23] Gupta, J. Termeer, K. Klostermann, J. Meijerink, S., Brink, M. Jong, Pieter, Nooteboom, S. Bergsma, E (2010): The Adaptive Capacity Wheel: A Method to Assess the Inherent Characteristics of Institutions to Enable the Adaptive Capacity of Society: Environmental Science \& Policy. 13, 6, p. 459-471 13 p..

[24] Hussain S. G. (2008) "Assessing Impact of Climate Change on Cereal Production and Food Security in Bangladesh" Paper Presented at the International Conference on Global Climate Change and its Effect, Dhaka, 25-30 August.

[25] IPCC (2007). Climate Change 2007: Impacts, Adaptation and Vulnerability. Contribution of Working Group II to the Fourth Assessment Report of the IPPC. Cambridge: Cambridge University Press. Pp. 869-883.

[26] Islam M. N., “Farmer's Perception and Agricultural Adaptation of Climate Changes in Drought Prone Area of Rajshahi Division", Unpublished Article.

[27] Kamruzzaman, M.: Farmers' Perceptions on Climate Change: A Step toward Climate Change Adaptation in Sylhet Hilly Region: Universal Journal of Agricultural Research 3 (2): 5358,2015

[28] Kendall, H. and Pimental, D (1994) "Constraints on the expansion of the global food supply" Ambio 23 (3), PP. 198205.

[29] Kuriakose, T. A. Bizikova, L. Bachofen, C. A. (2009) "Assessing Vulnerability and Adaptive Capacity to Climate Risks: Methods for Investigation at Local and National Levels" Social Development Working Papers; Paper No. 116. 
[30] Kurukulasuriya, Mendelsohn, 2008. A Ricardian analysis of the impact of climate change on African cropland. African Journal of Agricultural and Resource Economics 2 (1), 1-23.

[31] Leiserowitz, A. (2006): Climate Change Risk Perception and Policy Preferences: The Role of Affect, Imagery, and Values; Springer: July 2006, Volume 77, Issue 1, pp 45-72

[32] Mabe F. N., Sienso G. \& Donkoh S. (2014); "Determinants of Choice of Climate Change Adaptation Strategies in Northern Ghana" Research in Applied Economics ISSN 1948-5433, Vol. 6, No. 4.

[33] Mertz O, Mbow C, Reenberg A, Diouf A. (2009). Farmers' perceptions of climate change and agricultural adaptation strategies in rural Sahel. Environmental Management 43: 804816.

[34] McCarthy, O. F. Canziani, N. A. Leary, D. J. Dokken \& K. S. White (Eds.), ClimateChange 2001: Impacts, Adaptation, and Vulnerability - The Contribution of WorkingGroup II to the Third Scientific Assessment of the Intergovernmental Panel on Climate Change (Chapter 18) Cambridge University Press, Cambridge.

[35] MoEF. 2009. "Bangladesh Climate Change Strategy and Action Plan-2009" Ministry of Environment and Forests, Government of the People's Republic of Bangladesh, Dhaka, Bangladesh

[36] Moniruzzaman, M. (2013): People's Perception on Climate Change and Variability: A Study of Sabrang Union, Teknaf, Cox'sbazar, Bangladesh: ASA University Review, Vol. 7 No. 2, July-December, 2013.

[37] Molua, E., 2002. Climate Variability, Vulnerability and Effectiveness of Farm-Level Adaptation Options: The Challenges and Implications for Food Security in Southwestern Cameroon. Environment and Development Economics 7: 529-545.

[38] Nhemachena and Hassan R: Micro-Level Analysis of Farmers' Adaptation to Climate Change in Southern Africa. IFPRI Discussion Paper 00714 [2007];

[39] OECD 2009: Organization for Economic, Co-operations and Development: $<$ https://www.oecd.org $>$

[40] Okonya J. S., Syndikus K. \&Kroschel J. (2013) "Farmers' Perception of and Coping Strategies to Climate Change: Evidence from Six Agro-Ecological Zones of Uganda" Journal of Agricultural Science; Vol. 5, No. 8; 2013 ISSN 1916-9752.

[41] Omambia, A. N., Shemsanga, C., Li Y., [2009], "Combating Climate Change in Kenya: Efforts, Challenges and Opportunities" Report and Opinion, 2009; 1 (6).

[42] Rakib, M. and Anwar, S. M. H. (2016): Farmers' Perception And Knowledge of Climate Change in Bangladesh - An Empirical Analysis: Research in Agriculture, Livestock And Fisheries: V-3, P: 27-35

[43] Rahman, M. H., Matin M. A. (2015), "On the Prediction of Average Monsoon Rainfall in Bangladesh with Artificial Neural Network" International Journal of Computer Applications, Volume 127 - No. 5.

[44] UNDP (United Nations Development Programme) 2007, Human development report 2007/2008: Fighting climate change: human solidarity in a divided world, Palgrave Macmillan, New York.
[45] UNFCCC (2000): United Nations Framework Convention on Climate Change:

https://en.wikipedia.org/wiki/United Nations_Framework_Co nvention_on_Climate_Change

[46] Yusuf, A. and H. Francisco. 2009. Climate Change Vulnerability Mapping for Southeast Asia. Economy and Environment Program for Southeast Asia: Singapore.

[47] Wang, J. Mendelsohn, R. Dinar, A. Huang, J. Rozelle, S. Zhang, L., (2009): The impact of climate change on China's agriculture: Agriculture Economics 323-337

[48] Weber, E. U. (2010): What shapes perceptions of climate change? WIREs Climate Change: V-1, I-3, P-332-342.

[49] http://en.prothom-alo.com/sciencetechnology/news/87823/Bangladesh-ranked-sixth-in-risk-listClimate.

[50] Adger, W. N.; Huq, S.; Brown, K.; Conway, D. \& Hulme M. (2003) "Adaptation to Climate Change in the Developing World" Progress in Development Studies No. 3.

[51] Bryan, E., Deressa, T. T., Gbetibouo, G. A., Ringler, C., (2009): Adaption to Climate Change in Ethiopia and South Africa: Options and Constraints. Environ. Sci. Pol. 12, 413426.

[52] Nakuja, T., Sarpong, D. B., Kuwornu, J. K. M. and Aahante F. A. (2012). Water storage for dry season vegetable farming as an adaption to climate change in the upper east region of Ghana, African Journal of Agricultural Research, Vol. 7 (2), pp. 298-306.

[53] Masud. A, Liza. A. K and Azad, A. K. 2014. "Vulnerability of Crop Production to Climate Variability in a Water Stress Area of North-West Region of Bangladesh: A Case Study in the Sapahar Upazila Under Naogaon District". IOSR Journal of Environmental Science, Toxicology and Food Technology 8: 41-52.

[54] Sarkar, M. A. R. Alam, K. Gow, J. (2013), "Assessing the determinants of rice farmers' adaptation strategies to climate change in Bangladesh", International Journal of climate change strategies and Management, Vol. 5, Iss: 4, PP. 382-403.

[55] YUE, S., PILON, P. \& CAVADIAS, G. (2002). Power of the Mann-Kendall and Spearman's rho tests for detecting monotonic trends in hydrological series. Journal of hydrology, $259,254-271$.

[56] Sen Pk (1968) Estimates of the regression coefficient based on Kendall's tau; Journals of American Statistical Association: 39, 1379-1389

[57] Mabe, F. N., Sarpong, D. B., and Osei-Asare. Y. (2012). Adaptive Capacities to Climate Change Adaption Strategies and There effects on Rice Production in the Northen Region of Ghana, Russian Journal of Agricultural and SocioEconomic Sciences, No. 11 (11), pp. 9-17.

[58] Mia NM, (2003) Variations of temperature of Bangladesh. In Proceedings of SAARC Seminars on Climate Variability in the South Asian Region and its Impacts, SMRC, Dhaka.

[59] Chowdhury MHK, Debsharma SK (1992). Climate change in Bangladesh -A statistical review. Report on IOCUNEP workshop on impacts of sea level rise due to global warming, NOAMI, held during 16-19 November 1992, Bangladesh. 
[60] Parthasarathy B, Sontake NA, Monot AA, Kothawale DR (1987) Drought-flood in the summer monsoon season over different meteorological subdivisions of India for the period 1871-1984. J Climatology 7, pp 57-70.

[61] Divya, Mehrotra R (1995). Climate Change and hydrology with emphasis on the Indian subcontinent. J Hydro Sciences, 40, pp 231-241.

[62] Kulkarni, A., von Storch, H., (1995). Monte-Carlo experiments on the effect of serial correlation on the MannKendall test of trend. Meteorol. Z. 4 (2), 82-85

[63] von Storch, H., (1995). Misuses of statistical analysis in climate research. In: Storch, H. V., Navarra, A. (Eds.), Analysis of climate variability: applications of statistical techniques. Springer, Berlin, pp. 11-26.

[64] von Storch, H., Navarra, A., (1995). Analysis of Climate Variability - Applications of Statistical Techniques. Springer-Verlag, New York.

[65] Asante, F. A., Egyir, I. s., Jatoe, J. B. D. and Boakye, A. A. (2009). Emproving farming communities in Northen Ghana with Strategic Innovations and Productive Resources in Dryland farming- An Impact Assessment. A report prepared by the strategic innovations in Dryland farming project (PN 6) for the challenge program for food and water, Ghana.

[66] Partal, T., Kahya, E., (2006). Trend analysis in Turkish precipitation data. Hydrol. Process. 20, 2011-2026.

[67] Banjade, M. R., (2003). Local Perception and Use of Information for Forest User Groups: Case Studies from Dhankuta District, Nepal. MSc thesis Tropical Forestry. Wageningen University.

[68] RECOFTC, (2001). Information notes on networking and information management. International Conference on Advancing Community Forestry: Innovations and Experiences, Chiang Mai, 25-28 September 2001. www.recoftc.org/conference2001 information.html - 52k (12th Jan, 2002).

[69] Saarinen, T. F., (1976). Environmental planning: perception and behavior. Houghton Mifflin Comp. Boston.
[70] Banjade, M. R., (2003). Local Perception and Use of Information for Forest User Groups: Case Studies from Dhankuta District, Nepal. MSc thesis Tropical Forestry. Wageningen University.

[71] Katungi, EM (2007): Social Capital and Technology Adoption on Small Farms: The Case of Banana Production Technology in Uganda, $\mathrm{PhD}$ thesis, University of Pretoria.

[72] Katungi, E, Edmeades, S and Smale, M (2008): Gender, Social Capital and Information Exchange in Rural Uganda, Journal of International Development, 20, 113-19.

[73] Karmakar S, Shrestha ML (2000). Recent climate change in Bangladesh. SMRC No 4 SMRC, Dhaka.

[74] Klein, R. J. T. (2002). Climate Change, Adaptive capacity and Sustainable Development, OECD informal expert Meeting on Development and Climate Change-Paris, France, 13-14 March, 2002.

[75] Battese, G. E. (1997). A note on the estimation of CobbDouglas production functions when some explanatory variables have zero values. Journal of Agricultural Economics 48 (2): $250-252$.

[76] Onumah, E. E., Brummer, B. and Gabriele H. S. (2010). Elements Which Delimitate

[77] Gbetibouo, A. G. (2009), “ Understanding Farmer's Perception And Adaptions to Climate Change Variability": IFPRI Discussion Paper 0849

[78] Roy, M. (2013), "Time Series, Factors and Impacts Analysis of Rainfall in North-Eastern Part in Bangladesh" International Journal of Scientific and Research Publications, Volume 3, Issue 8, August 20131 ISSN 2250-3153

[79] Zakaria, M., Aziz, M. A., Hossain, I. M., Rahman, N. M. F. (2014), "Effects Of Rainfall And Maximum Temperature On Aman Rice Production Of Bangladesh: A Case Study For Last Decade": International Journal of Scientific \& Technology Research: V- 3, I- 2, ISSN 2277-8616. 